\title{
Nurses Awareness Regarding their Competence in Managing Patient Situations
}

\author{
Hanaa Esmail Sabra ${ }^{1}$, Shymaa Helmy Ahmed ${ }^{2}$, Asmaa Mohamed Ahmed ${ }^{3}$ \\ 1. Assistant Professor of Nursing Administration Department, Faculty of Nursing, South Valley University, Quena, \\ Egypt \\ 2. Lecturer of Adult Nursing Department, Faculty of Nursing, South Valley University, Quena, Egypt \\ ${ }^{3 .}$ Lecturer of Nursing Administration Department, Faculty of Nursing, South Valley University, Quena, Egypt
}

\begin{abstract}
:
Nurses are basic group in health care settings, and their competences have a major role in the quality of health services. Aim: To examine the nurses awareness regarding their competence in managing patients' situations and exploring the competence level among them. Design: Descriptive explorative design was used. Subjects: Convenient sample comprised of 150 nurses who had at least two years of experience who work in medical, surgical, ICUs and gynecological units at Quena University Hospital. Tools: Nurse Competence Scale was used for data collection. Results: Main result for this study indicated that about $68.7 \%$ of studied nurses had a good level of competence of managing patient situations, while; only $14.7 \%$ had excellent level. The highest mean score of managing patient situations domains was related to; reporting the results to the physician and other healthcare members while, the lowest was related to; updating nursing care plan. Conclusion: Education level, years of experience in units, obtaining any certification or sharing in advanced life support program like CPR and achieve training in different specialty were factors linked to nurses clinical competence and influenced it. Recommendations: Nursing Managers must plan educational programs to develop nurses' competence from good level to excellent, and provide opportunity for nurses to achieve training in different specialties as incentive for professional growth and nursing administrators should organize nurses for success by establishing systems for warranting chances for knowledge and skills acquirement required for safety nursing practice and the high health level services.
\end{abstract}

\section{Keywords: Nurses, Awareness, Competence, Managing \& Patient Situations}

\section{Introduction:}

Nowadays, there is a great challenge posed by an ageing population, increasing globalization, growth of technology, and pervasiveness of chronic diseases and disabilities required for changing the healthcare delivery systems. This unstable nature in healthcare settings requires nurses at higher level of competence to manage different patients' situations (Berhanu et al., 2016 \& Lane \& Ross, 2016).

Competency is a favorite as product of nursing education and professional development. It is sometimes equaled with performance and capacity to perform according to predetermined standard. The conception of competence and performance are two distinguishing conceptions which are closely linked. A performance relates to an action that is an accomplishment while, competence is the ability to deliver a performance in different circumstances. The component of competence thus represents the competency to convert sub skills (perceptive, social, emotive, and sensorimotor), knowledge, values and attitudes into desired actions. (ANA 2012, \& Lavoie et al., 2018).

According to Benner, (1984) cited in Donna., (2013) nurse generally passes thorough at minimum five phases of different awareness of his task and as his skills develops". They includes; novice, advanced beginner, competent, proficient, and expert. Phases are mentioned because each individual, when confronting a particular type of situation in his or her skill domain, will usually approach it first in the manner of the novice, then of the advanced beginner, and so on until reach expert. Competence is attitude, and skill to achieve a particular duty in a method that produces wanted results. However, this definition differs, according to level of professional education and experience (European Federation of Nurses Association, 2013, \& Lima et al., 2014).

Competence in nursing profession is vivacious for confirming the quality of patient safety and it is a basic for staff growth departments in health care settings. The ability of nurses to provide nursing care for patients in competent manner is linked to their knowledge and skills within their scopes of professional practice. Develop teaching strategies that will help expect competent practice is a defying for nursing educators. Nursing competence is the nurses' capability to accomplish nursing responsibilities efficiently to incorporate intellectual, emotive, and psychomotor skills during patient care. 
There is essential for clinical competence like a professional accountability and public concern. (O'Connell \& Gardner, 2014 \& International Council of Nurses, 2016).

Recently the clinical competence of nurses in health care setting is a major focus for health care Policy Makers. Deficiency of nurses' clinical competence considers a major problem that impacts the delivery of desired health care services. So, the requirement to improvement nursing educational programs through more concentration on clinical competence is required for achieve higher level of quality patients' care. Clinically competent professional nurses are capable of evaluation the level of patient awareness, observe indirect fluctuations in the patient's situation, effectively transfer this, provide the appropriate treatment and care with sympathy and comprehension (Levy-Malmberg, 2014 \& Fuentes et al., 2017).

\section{Significance of the study:}

Clinical status of patient can change quickly in hospital care units, nurses should have capacity for recognize and respond excellently and hastily to any changes. Health care organizations have focused great concentration in precluding adverse events or results and near misses. Nurses have $24 \mathrm{hrs}$. /day patient contact; they responsible for recognizing and reporting any change in patient situation that indicative to worsening his state. nurses' consciousness to their competency in managing this changing in patients situations represent challenging for higher authority in health care settings. Warranting aptitude in detecting and managing these events is a main importance. For this reasons, the researchers were conducted this study at Quena University Hospital to examine the nurses awareness regarding their competence in managing patients' situations.

\section{Aim of the study:}

To examine the nurses awareness regarding their competence in managing patients' situations and explore the level of competence among them.

\section{Specific objectives:}

1. To determine nurses' awareness regarding their competence in managing patients' situations.

2. To assess the competence level among nurses.

3. Explore relationship between nurse's awareness of their competence and their personal characteristics.

\section{Research Questions}

1. What is nurses' awareness regarding their competence in managing patients' situations at Quena University Hospital?

2. What is the level of competence among nurses?
3. Is there a relation between nurse's awareness of their competence and their personal characteristics?

\section{Materials and Methods \\ I-Technical design \\ Study Design: A descriptive explorative design was used.}

Study Setting: This study was carried out in medical, surgical, gynecological departments and ICUs units at Quena University Hospital.

Study Duration: The present study took about one year from January 2020 until January 2021.

Sample size: The study involved convenient sample comprised of 150 nurses representing all available nurses who are on duty in selected study settings, nurses were recruited based on the following inclusion criteria; staff nurses had at least two years of experience in their working place at the time of study.

\section{Data Collection Tools:}

Nurse Competence Scale (NCS) was used for data collection. It was established by Meretoja et al., (2004) for examining nurses' awareness of their own competence. It contained two parts.

Part one: Included information related to personal characteristics (Age, sex, social status, qualification, years of experience in nursing, and current unit, work setting) and job training and achievements (attainment any certification in advanced life support (ALS), participation in ALS for patient, sharing in ALS program like CPR, achieve training in different specialty and attendance a case review session).

Part two: Which related to aspects of managing patient situations, under two dimensions; Managing situations (6) aspects (reporting the results to the physician and other healthcare members, communicate relevant information about patient's health situation, seeking clarification from the physician about the treatment plan, assessing the patient's reaction to treatment, updating nursing care plan, and conclude knowledge from the experience to use it in managing new patient situations) and therapeutic intervention (7) aspects (decide action based on decision making skills, recognizing signs and symptoms of deterioration in patient's clinical condition, taking action to manage patient's changing situation, making assessment for priority of actions, preparing resources to help in delivery of patient care, understanding reason for actions and orders and replicating on your procedure of managing fluctuating patient situations).

Scoring System:

Studied nurses were requested to allocate a score to their awareness for their competence in aspects of 
managing patient situations according to visual analogue scale (VAS). The scale ranged from 0 to 10 , with 0 being the lowest, and 10 being the highest. The questionnaire was labeled as: 0-2 (weak); 3-5 (moderate); 6-8 (good) and 9-10 (excellent). The score of each aspect were summed up and then changed into a percentages score. The scoring levels were organized as follow; from 0 to less than $25 \%$ as a weak awareness, from 25 to $>50 \%$ as moderate awareness; from 50 to $>75 \%$ as good awareness, and from 75 to $100 \%$ as excellent awareness.

Validity of the Study Tool: The draft of questionnaire was reviewed for face validity by five experts from faculties of nursing in the field of education from administration department at Quena and Assiut Universities. Content validity was measured using confirmatory factors analysis to assure (importance, clearance, and accountability) of all items of study tools, all items obtained more than 1.5 so all of tools items were confirmed.

II-Administrative Design: Formal permission was obtained from the responsible authorities. The researchers met departments' supervisors to explain study aim to them, to obtain their approval and support, and to organize the nurses' contribution based on the nature of work on each department.

III-Operational Design: It explains steps of actual implementation of the study, and includes preparatory phase, pilot study, and field work.

Preparatory phase: It took about two months started in January 2020 to end of February 2020 which included reviewing related literatures. Tools were translated into Arabic and retranslated into English for correctness.

\section{Pilot Study:}

A pilot study was conducted on a sample of $10 \%$ of participants to assess clarity, applicability, reliability of the tool, and to evaluate the time required for reply it. It also assisted to assess the feasibility and suitability of the study settings. Data attained from the pilot study were analyzed; no alterations were done, so, the subjects participated in the pilot study were included in the study sample.

\section{Reliability:}

reliability of the study tool was evaluated in pilot study by measuring their internal consistency using Cronbchs alpha is $(\alpha=0.867)$ for study tool, thus Pointing to a high degree of reliability.

\section{Field Work:}

After warranting the simplicity and suitability of study tool, the researchers met with participants' to elucidate study aim to them, and to get oral consent for contribution; then, the researchers distributed the questionnaire to them, one researcher remained with them for any explanation. Data were collected in different shifts based on work schedule of each unit. The self-administered questionnaire took about 20 minutes for each participant to be filled. Data collection stage took about two months started in March 2020 until the end of April 2020.

\section{Ethical Consideration}

To conduct this study at selected study settings an official permission obtained from the responsible authorities. The researchers met with units' supervisors to clarify study aim to them, to obtain their approval and support, and organizing the participants based on nature of work of each unit. Oral agreements were attained from participants and they informed that their participation is voluntary on that they have the right to agree or disagree to participate in the study without providing any reason. Moreover, secrecy of gathered information and privacy of the participants was assured.

\section{Statistical Analysis:}

Data were collected and fed into computer for analysis and presentation. Data entry and analysis were done using SPSS version 19. Data were presented using descriptive statistics as number, percentage, mean, standard deviation. Spearman correlations were done to measure correlation between quantitative variables. P-value considered statistically significant when $\mathrm{P}<0.05$. 


\section{Results:}

Table (1): Personal Characteristics of Studied Nurses $($ No $=150)$

\begin{tabular}{|c|c|c|}
\hline Personal Characteristic & No. (150) & $\%$ \\
\hline \multicolumn{3}{|l|}{ Age: (years) } \\
\hline$<25$ & 63 & 42.0 \\
\hline $25-<30$ & 45 & 30.0 \\
\hline$\geq 30$ & 42 & 28.0 \\
\hline Mean \pm SD (Range) & \multicolumn{2}{|c|}{$27.15 \pm 5.20(20.0-48.0)$} \\
\hline \multicolumn{3}{|l|}{ Sex: } \\
\hline Male & 46 & 30.7 \\
\hline Female & 104 & 69.3 \\
\hline \multicolumn{3}{|l|}{ Marital status: } \\
\hline Single & 54 & 36.0 \\
\hline Married & 96 & 64.0 \\
\hline \multicolumn{3}{|l|}{ Qualification: } \\
\hline Nursing secondary school diploma & 69 & 46.0 \\
\hline Technical institute of nursing & 81 & $\mathbf{5 4 . 0}$ \\
\hline \multicolumn{3}{|l|}{ Years of experience in nursing: } \\
\hline $2<5$ & 47 & 31.3 \\
\hline $5-<10$ & 45 & 30.0 \\
\hline$\geq 10$ & 58 & 38.7 \\
\hline \multicolumn{3}{|l|}{ Years of experience in department: } \\
\hline $2<5$ & 69 & 46.0 \\
\hline $5-<10$ & 47 & 31.3 \\
\hline$\geq 10$ & 34 & 22.7 \\
\hline \multicolumn{3}{|l|}{ Work setting: } \\
\hline Medical & 64 & 42.7 \\
\hline Surgical & 34 & 22.7 \\
\hline ICUs & 30 & 20.0 \\
\hline Gynecology & 22 & 14.7 \\
\hline \multicolumn{3}{|c|}{ Attainment any certification in advanced life support : } \\
\hline Yes & 107 & 71.3 \\
\hline No & 43 & 28.7 \\
\hline \multicolumn{3}{|l|}{ Place: } \\
\hline Inside the hospital & 54 & $\mathbf{5 0 . 5}$ \\
\hline Outside the hospital & 53 & 49.5 \\
\hline \multicolumn{3}{|c|}{ Participation in advanced life support for patient: } \\
\hline Yes & 104 & 69.3 \\
\hline No & 46 & 30.7 \\
\hline \multicolumn{3}{|c|}{$\begin{array}{l}\text { Sharing in advanced life support } \\
\text { cardiopulmonary resuscitation CPR: }\end{array}$} \\
\hline Yes & 84 & $\mathbf{5 6 . 0}$ \\
\hline No & 66 & 44.0 \\
\hline \multicolumn{3}{|l|}{ Achieve training in different specialty: } \\
\hline Yes & 82 & 54.7 \\
\hline No & 68 & 45.3 \\
\hline \multicolumn{3}{|c|}{ Do you feel a case review session benefited your practice? } \\
\hline Yes & 114 & 76.0 \\
\hline No & 36 & 24.0 \\
\hline
\end{tabular}


Table (2): Mean Scores of Studied Nurses Awareness Regarding their Competence in Managing Patient Situations (NCS) $($ No $=150)$

\begin{tabular}{|l|c|c|}
\hline \multicolumn{1}{|c|}{ Aspects of NCS } & Mean \pm SD & Range \\
\hline Managing Patient Situation Domains & $\mathbf{6 . 9 2} \pm \mathbf{2 . 2 2}$ & $1.0-9.0$ \\
\hline Reporting the results to the physician and other healthcare members & $\mathbf{6 . 6 5} \pm \mathbf{2 . 2 9}$ & $1.0-9.0$ \\
\hline Communicate relevant information about patient's health situation & $\mathbf{6 . 4 1} \pm \mathbf{2 . 0 6}$ & $1.0-9.0$ \\
\hline Asking the physician for elucidate the treatment plan of patient & $6.09 \pm 2.16$ & $1.0-9.0$ \\
\hline Assessing the patient's reaction to treatment & $5.89 \pm 1.97$ & $1.0-9.0$ \\
\hline Updating nursing care plan & $5.99 \pm 1.88$ & $1.0-9.0$ \\
\hline $\begin{array}{l}\text { Conclude knowledge from the experience to use it in managing new patient } \\
\text { situations }\end{array}$ & $\mathbf{6 . 4 9} \pm \mathbf{1 . 5 4}$ & $1.2-8.3$ \\
\hline Total & $6.37 \pm 2.06$ & $1.0-9.0$ \\
\hline Therapeutic Interventions Domains & $6.35 \pm 1.99$ & $1.0-10.0$ \\
\hline Decide action based on decision making skills & $6.52 \pm 1.76$ & $1.0-9.0$ \\
\hline Identifying marks and symptoms of worsening in patient's clinical state & $\mathbf{6 . 5 9} \pm \mathbf{1 . 9 6}$ & $1.0-10.0$ \\
\hline Taking responsibility for manage patient's varying statuses & $\mathbf{6 . 7 4} \pm \mathbf{1 . 9 3}$ & $1.0-9.0$ \\
\hline Making assessment for priority of actions & $\mathbf{6 . 7 9} \pm \mathbf{2 . 3 5}$ & $1.0-9.0$ \\
\hline Preparing resources to help in delivery of patient care & $5.95 \pm 2.08$ & $1.0-9.0$ \\
\hline Understanding reason for actions and orders & $\mathbf{6 . 3 3} \pm \mathbf{1 . 5 8}$ & $\mathbf{1 . 1 - 8 . 3}$ \\
\hline Replicating on your procedure of managing fluctuating patient situations & $\mathbf{6 . 4 1} \pm \mathbf{1 . 5 1}$ & $1.3-8.2$ \\
\hline Total
\end{tabular}

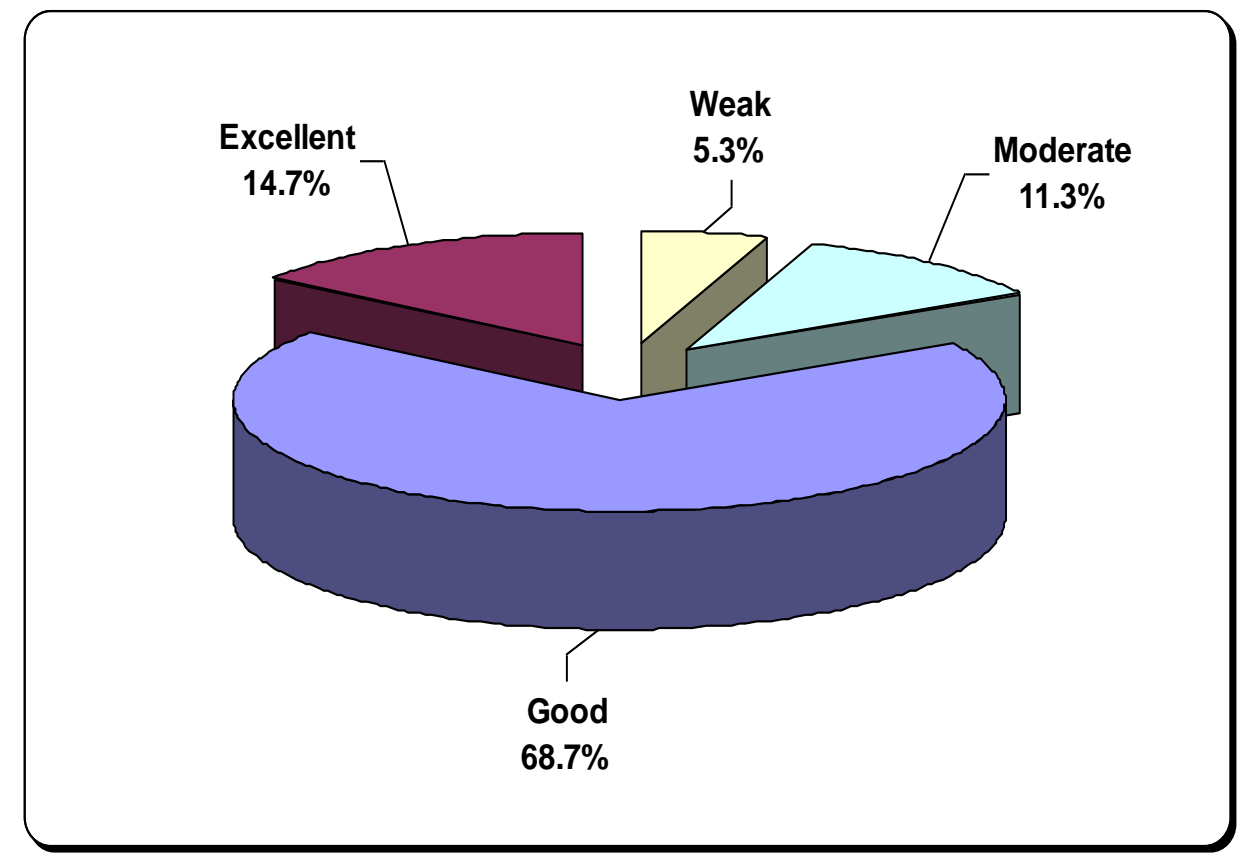

Figure (1): Distribution Levels of Competence of Studies Nurses ( $=150)$ 
Table (3): Correlation between Studied Nurses Awareness Regarding their Competence in Managing Patients Situations and their Personal Characteristics (No = 150)

\begin{tabular}{|c|c|c|c|}
\hline \multirow[t]{2}{*}{ Items } & $\begin{array}{l}\text { Therapeutic } \\
\text { interventions }\end{array}$ & $\begin{array}{c}\text { Managing patient } \\
\text { situation }\end{array}$ & Total competence \\
\hline & Mean \pm SD & Mean \pm SD & Mean \pm SD \\
\hline \multicolumn{4}{|l|}{ Age: (years) } \\
\hline$<25$ & $6.49 \pm 1.48$ & $6.67 \pm 1.49$ & $6.58 \pm 1.46$ \\
\hline $25-<30$ & $6.08 \pm 1.75$ & $6.32 \pm 1.62$ & $6.19 \pm 1.65$ \\
\hline$\geq 30$ & $6.37 \pm 1.55$ & $6.40 \pm 1.52$ & $6.38 \pm 1.44$ \\
\hline P-value & 0.404 & 0.470 & 0.430 \\
\hline \multicolumn{4}{|l|}{ Sex: } \\
\hline Male & $6.65 \pm 1.34$ & $6.85 \pm 1.35$ & $6.74 \pm 1.30$ \\
\hline Female & $6.19 \pm 1.67$ & $6.33 \pm 1.59$ & $6.26 \pm 1.58$ \\
\hline P-value & 0.103 & 0.056 & 0.069 \\
\hline \multicolumn{4}{|l|}{ Marital status: } \\
\hline Single & $6.25 \pm 1.84$ & $6.43 \pm 1.91$ & $6.33 \pm 1.84$ \\
\hline Married & $6.38 \pm 1.43$ & $6.53 \pm 1.29$ & $6.45 \pm 1.30$ \\
\hline P-value & 0.632 & 0.712 & 0.658 \\
\hline \multicolumn{4}{|l|}{ Education level: } \\
\hline Nursing secondary school diploma & $5.73 \pm 2.01$ & $6.06 \pm 1.96$ & $5.88 \pm 1.93$ \\
\hline Technical institute of nursing & $6.85 \pm 0.81$ & $6.86 \pm 0.91$ & $6.86 \pm 0.80$ \\
\hline P-value & $0.000 *$ & $0.001 *$ & $0.000 *$ \\
\hline \multicolumn{4}{|l|}{ Years of experience in nursing: } \\
\hline $2<5$ & $6.53 \pm 1.35$ & $6.78 \pm 1.34$ & $6.64 \pm 1.32$ \\
\hline $5-<10$ & $6.33 \pm 1.79$ & $6.35 \pm 1.81$ & $6.34 \pm 1.77$ \\
\hline$\geq 10$ & $6.18 \pm 1.60$ & $6.37 \pm 1.45$ & $6.27 \pm 1.44$ \\
\hline P-value & 0.542 & 0.308 & 0.427 \\
\hline \multicolumn{4}{|l|}{ Years of experience in units: } \\
\hline $2<5$ & $6.60 \pm 1.33$ & $6.64 \pm 1.42$ & $6.62 \pm 1.32$ \\
\hline $5-<10$ & $6.32 \pm 1.92$ & $6.31 \pm 1.84$ & $6.46 \pm 1.85$ \\
\hline$\geq 10$ & $6.14 \pm 1.51$ & $6.03 \pm 1.30$ & $6.13 \pm 1.34$ \\
\hline P-value & $\mathbf{0 . 0 1 4} *$ & $0.010 *$ & $\mathbf{0 . 0 2 5 *}$ \\
\hline \multicolumn{4}{|l|}{ Work setting: } \\
\hline Medicine & $6.04 \pm 1.88$ & $6.28 \pm 1.78$ & $6.15 \pm 1.79$ \\
\hline Surgery & $6.30 \pm 1.60$ & $6.51 \pm 1.38$ & $6.40 \pm 1.47$ \\
\hline ICU & $6.84 \pm 0.69$ & $6.74 \pm 1.34$ & $6.79 \pm 0.92$ \\
\hline Gynecology & $6.55 \pm 1.35$ & $6.72 \pm 1.24$ & $6.63 \pm 1.26$ \\
\hline P-value & 0.128 & 0.490 & 0.239 \\
\hline
\end{tabular}

(*) Statistically significant differences at $p<0.05$ 
Table (4): Correlation between Studied nurses Awareness Regarding their Competence in Managing Patient Situations and their attainment any certification in ALS, participation in ALS for patient, sharing in ALS program like CPR, achieve training in different specialty and attendance a case review session $($ No $=150)$

\begin{tabular}{|c|c|c|c|}
\hline \multirow[t]{2}{*}{ Items } & $\begin{array}{l}\text { Therapeutic } \\
\text { interventions }\end{array}$ & $\begin{array}{c}\text { Managing patient } \\
\text { situation }\end{array}$ & Total competence \\
\hline & Mean \pm SD & Mean \pm SD & Mean \pm SD \\
\hline \multicolumn{4}{|c|}{$\begin{array}{l}\text { Attainment any certification in advanced } \\
\text { life support }\end{array}$} \\
\hline Yes & $6.86 \pm 0.87$ & $7.02 \pm 0.85$ & $6.94 \pm 0.82$ \\
\hline No & $5.02 \pm 2.13$ & $5.16 \pm 2.00$ & $5.09 \pm 1.98$ \\
\hline P-value & $0.000 *$ & $0.000 *$ & $0.000^{*}$ \\
\hline \multicolumn{4}{|l|}{ Place: } \\
\hline Inside the hospital & $6.85 \pm 0.90$ & $7.08 \pm 0.94$ & $6.96 \pm 0.88$ \\
\hline Outside the hospital & $6.87 \pm 0.84$ & $6.97 \pm 0.76$ & $6.92 \pm 0.75$ \\
\hline P-value & 0.899 & 0.525 & 0.815 \\
\hline \multicolumn{4}{|c|}{$\begin{array}{l}\text { Participation in advanced life support for } \\
\text { patient: }\end{array}$} \\
\hline Yes & $6.31 \pm 1.56$ & $6.55 \pm 1.50$ & $6.42 \pm 1.50$ \\
\hline No & $6.39 \pm 1.65$ & $6.35 \pm 1.63$ & $6.37 \pm 1.57$ \\
\hline P-value & 0.783 & 0.461 & 0.849 \\
\hline \multicolumn{4}{|c|}{$\begin{array}{l}\text { Sharing in advanced life support program } \\
\text { like cardiopulmonary resuscitation CPR }\end{array}$} \\
\hline Yes & $6.63 \pm 1.42$ & $6.78 \pm 1.39$ & $6.80 \pm 1.36$ \\
\hline No & $6.08 \pm 1.75$ & $6.15 \pm 1.69$ & $6.16 \pm 1.67$ \\
\hline$P$-value & 0.018* & $0.028 *$ & $0.017 *$ \\
\hline \multicolumn{4}{|c|}{ Achieve training in different specialty } \\
\hline Yes & $6.47 \pm 1.52$ & $6.72 \pm 1.34$ & $6.59 \pm 1.39$ \\
\hline No & $6.17 \pm 1.65$ & $6.21 \pm 1.72$ & $6.19 \pm 1.63$ \\
\hline P-value & 0.243 & $0.041 *$ & 0.107 \\
\hline \multicolumn{4}{|c|}{$\begin{array}{l}\text { Do you feel a case review session benefited } \\
\text { your practice? }\end{array}$} \\
\hline Yes & $6.29 \pm 1.64$ & $6.46 \pm 1.57$ & $6.37 \pm 1.56$ \\
\hline No & $6.48 \pm 1.39$ & $6.58 \pm 1.43$ & $6.53 \pm 1.37$ \\
\hline P-value & 0.517 & 0.681 & 0.577 \\
\hline
\end{tabular}

(*) statistically significant differences at $p<0.05$ 


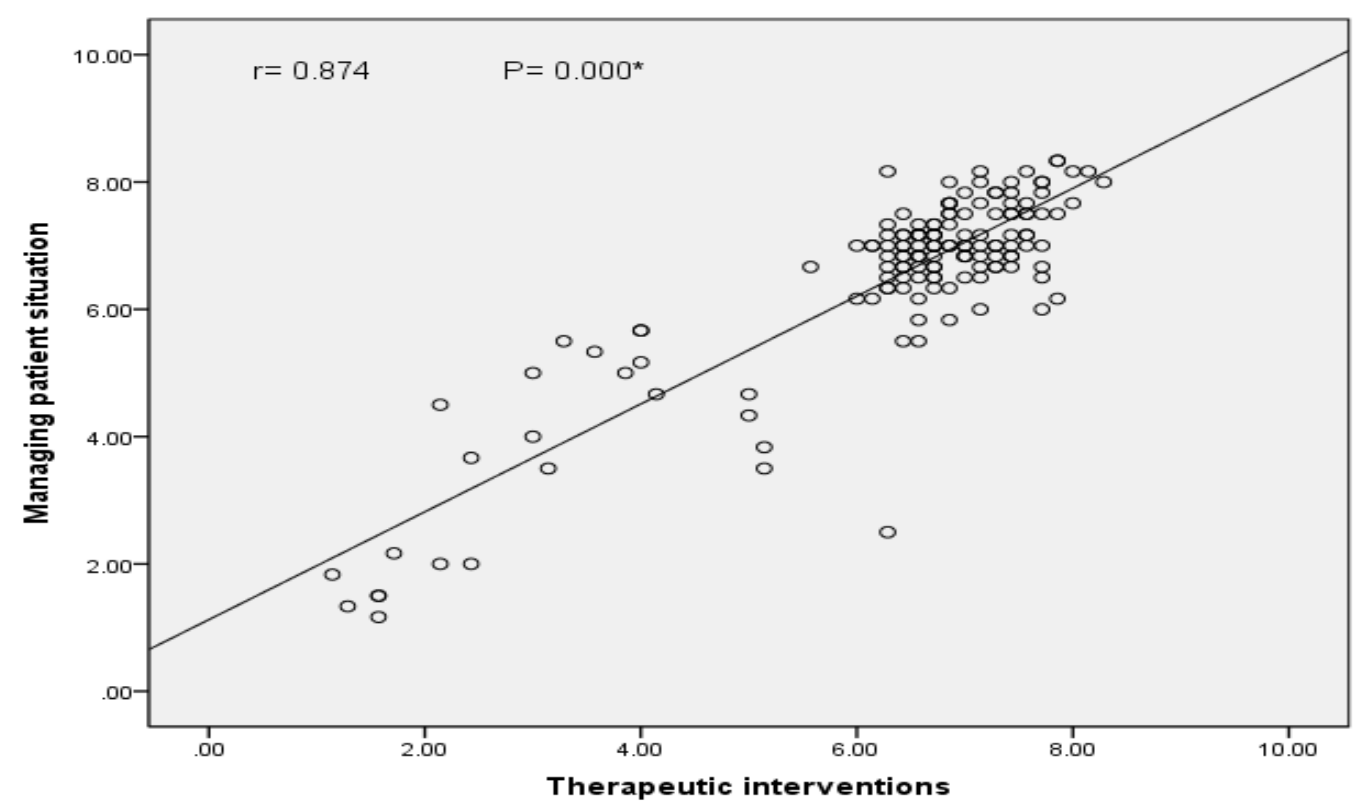

\section{Figure (2): Correlation between Therapeutic Intervention and Managing Patient Situations Domains as Perceived by Participants $(\mathrm{N}=150)$}

Table (1): Reveals personal characteristics of studied nurses. The data in this table demonstrated that the study nurses working in, medical, surgical, ICUs and gynecology units', number of them were 150, about $(42.0 \%)$ of them had their age less than 25 years, more than two third of them $(69.3 \%)$ were females, slightly less than two third of them $(64.0 \%)$ were married, about $(54.0 \%)$ of them had technical Institute of nursing. while $(46.0 \%)$ of them had nursing secondary school diploma nursing. about $(38.7 \%)$ of them had $\geq 10$ years of experience in nursing, about $(46.0 \%)$ of them had from 2 to $<5$ years of experience in nursing department. It was observed that about $(71.3 \%)$ of them had attainment certification in advanced life support, about (69.3\%) of them Participation in advanced life support for patient, about $(56.0 \%)$ of them had Sharing in advanced life support training like CPR, about $(54.7 \%)$ of them achieve training in different specialty and about $(76.0 \%)$ of them had feel a case review session benefited their practice.

Table (2): Shows mean scores of studied nurses' awareness regarding their competence in managing patient situations. The data in table revealed that in relation to managing situations domain nurses had highest mean score in three aspect; reporting the results to the physician and other healthcare members $(6.92 \pm \mathbf{2 . 2 2}$ communicate relevant information about patient's health situation $(6.65 \pm 2.29)$ and asking the physician for elucidate the treatment plan of patient (6.41 \pm 2.06). Also, in relation to therapeutic interventions domain nurses have had highest mean in three aspect; understanding reason for actions and orders $(6.79 \pm 2.35)$, preparing resources to help in delivery of patient care $(6.74 \pm \mathbf{1 . 9 3})$ and making assessment for priority of actions $(\mathbf{6 . 5 9} \pm \mathbf{1 . 9 6})$.

Figure: (1): Depicts distribution levels of competence of studied nurses. The figure revealed that about $(68.7 \%)$ of participants had good level of competence while, about $(14.7 \%)$ of them had excellent level of competence.

Table (3): Shows correlation between studied nurses' awareness regarding their competence in managing patient situations and their personal characteristics. It was declared that there was positive statistically significant relation between therapeutic interventions, managing patient situation domains, total competence and education level and the utmost mean score were related to technical institute of nursing with (P value $\mathbf{= 0 . 0 0 0} *$ for all. Also, there were positive statistically significant relation between therapeutic interventions, managing patient situation domains, total competence, and years of experience in units and the utmost mean score were related to nurses $2<5$ years of experience with $\left(\mathbf{P}\right.$ value $=0.014^{*}, 0.010^{*}$ and $\left.\mathbf{0 . 0 2 5}^{*}\right)$ respectively.

Table (4): Demonstrated that there were positive statistically significant relation between therapeutic interventions domain, managing patient situation domain, total competence and obtaining any certification or training in advanced life support, sharing in advanced life support program like CPR 
with $(\mathbf{P}$ value $=0.000 *, 0.000 *$ and $0.000 *)$, and $(\mathbf{P}$ value $=0.018 *, 0.028 *$ and $0.017 *)$ respectively. Also, there was positive statistically significant relation between managing patient situation domain and achieved training in different specialty with ( $\mathrm{P}$ value $=0.041 *)$.

Figure (2): Shows correlation between therapeutic interventions and managing patient situations domains (Nurse Competence Subscales) as perceived by participants. The figure demonstrated that the therapeutic Interventions domain had highly positive statistically significant correlation with Managing patient Situations $(\mathbf{r}=\mathbf{0 . 8 7 4}$ and $\mathbf{p}$. value $=\mathbf{0 . 0 0 0})$.

\section{Discussion:}

The consideration of competence in nursing practice is obvious in the literature like the clinical environment. Competence awareness helps staff nurses to deliver good quality patient care (Blackburn et al., 2019). This study aimed to examine the nurse's awareness regarding their competence in managing patients' situations and explore the level of competence among them.

According to results in our study as revealed in table 1, more than two third of the studied nurses were female, signifying that nursing is still a female's profession this finding is confirmed by NandiNdeitwa, (2008) cited in sabra et al., 2018) who stated that women succeeded in care-related work as teaching, domestic work, and nursing. Also, the findings showed that slightly more than half of them had technical institute of nursing. This proved that nurses in Egypt began recognizing the importance of progress their education. In addition, slightly less than third of nurses had from 5 to $<10$ years of experience in nursing units and slightly more than third of them had $\geq 10$ years' experience in nursing units. This is similar to other study findings done by Donna, (2013) found more than two third of nurses had more than 6 years of experience.

From the finding analysis, more than two third of studied nurses had certification in advanced life support, more than two third of them participate in advanced life support for patient and slightly more than half of them achieved training in different specialty. This may explain the fact that participants have desire to improve their abilities, understanding, and personal accomplishment in their work through training and the hospital supported them. This result is supported by Blazun et al., (2015) confirm that specialty achievement in nursing has been helping to improve nurses' inherent awareness of knowledge, skill, and self- assurance. According to the Notarnicola et al., (2016) the professional training programs are giving for help in professional progress, and nurses' certification endorses their abilities, empowers them in their clinical practice and in improving patient outcomes.

On other hand, our study results demonstrated that more than three quarters of studied nurses were agreed that a case review session benefited their practice. In agreement with Pijl-Zeibr et al., (2014) who stated that use of real patient case-based teaching in nursing, as nursing round, helping staff nurses to advance habits of thought important to practice. In the same context, Lima et al., (2014) emphasized that case review provides chance for teachers to simplify clinical reasoning, enhance nursing competence, and critical thinking and increase their confidence in managing critical patient situations.

Regarding to mean scores of studied nurses' awareness regarding their competence in managing patient situations, it was observed that nurses perceived themselves as competent in managing patient situations for good range in majority of items as indicated by the most frequent scores (Table 2). This result supported by Donna, (2013) who found that her participants perceived their competency to manage patients' situations as good. It was noticed that in relation to, managing patient situation domain, nurses had highest mean score in three aspect; reporting the results to the physician and other healthcare members, communicate relevant information about patient's health situation and asking the physician for elucidate the treatment plan of patient (Table 2). This due to nature of traditional processes in nursing profession that nurses communicate information from shift to shift and report patient status to physician. This consistent with (Sharp et al., 2016) asserted that nurses ability to communicate in assertive and meaningful manner and their general appearance are crucial elements to connect with patient and manage his situation. Also, Foronda, et al., (2017) \& Lisa, (2019) emphasized that transmission and connecting pertinent information about patient among health care team is crucial for providing continuity of care, and lack communication between them can lead to adverse effect on patients' safety.

On other hand, studied nurses had moderate mean score in two aspect; updating nursing care plan and conclude knowledge from the experience to use it in managing new patient situations (Table 2). This result in contrast with Carrington \& Effken, (2017) who emphasis that updating plan of care is vital to record patient situation, medical treatment and nursing interventions and patient response to them, note patient progress and documenting care has been implemented by nursing. Also, Beogo et al., (2016) 
mentioned that reflection- on performance "passes through a better comprehension of practice and consider a significant manner in which nurses acquire from their experience" and it is essential component in the development of nursing competence.

In addition, the results declared that studied nurses had highest mean score in assessing the patient's reaction to treatment more than, updating nursing care plan and conclude knowledge from the experience to use it in managing new patient situations (Table 2). These due to nurses have close contact with patients and monitoring them continually and they perceived their competence in assessing patient's response to interventions as good. In congruence with these finding Benner, (1984) cited in Donna, (2013) stated that the evaluation for the patient's reaction to interventions is a significant and the observing for therapeutic effects can have life and death consequences.

Regarding to therapeutic interventions domain, the study result discovered that studied nurses perceived their competence good but, they have had utmost mean score in three items; understanding reason for actions and orders, preparing resources to help in delivery of patient care and making assessment for priority of actions (Table 2). This indicated that studied nurses perceived themselves that they had intelligent skills in the delivery of patient care. These findings consistent with Iolya, (2014) who emphasized that early detecting of signs of worsening and initiating the assisting in appropriate time to rescue patients can prevent additional complication. In the same line Numminen et al., (2017) asserted that nurses confidence and their reinforcement in calling for assistance and availability of necessary resources are main elements that help in managing worsening patients situations.

According to results in our study as declared in Figure 1, more than two third of studied nurses had good level of competence and only slightly less than fifteen percent of them reported it as excellent. This finding congruence with Wangensteen et al., (2010) found that more than three quarters of participants had good level of competence and only sixteen percent of them reported it as very good. Inconsistent with Meretoja \& Koponen, (2012) who found that nurses' competence at optimal level of competence the difference may be due to difference in clinical teaching environment, educational strategies and the dissimilarities of the socioeconomic position of the country.

Results in table 3 displayed that there were statistical relation significant between therapeutic interventions, managing patient situation domains and total competence and education level, with technical institute of nursing more competent compared to nursing secondary school diploma. This attributed to that the long period of the teaching offers them additional opportunity to simplify and demonstrate the diverse processes that may participate to their competence. This confirmed by Aiken et al., (2013) found that lesser mortality related to percentage of bachelor degree participants. In the same line Zhang \& Fan (2015) asserted that hospitals need to increase percentage of nurses' bachelor degree graduates and provide opportunity for continuing education for nurses to meet requirements diversity in patient care.

Also, there were statistical relation significant between therapeutic interventions, managing patient situation domains and total competence and years of experience in units, and more competent nurses had their experience from 2 to $<5$ years (table 3). This in contrast with Kajander, (2014) indicated that nurse when do in specific one area may achieve awareness with this area, and the experience with patients and with other circumstances will increase her practical base of awareness and talent. Also, Kielo et al., (2016) emphasized that the experience helping the nurses' to become experts in their performance and it provide them with fundamentals for growth of clinical knowledge and career advance.

Also the result in table $\mathbf{3}$ didn't reveal any statistical relation significant between therapeutic interventions, managing patient situation domains and total competence and age, sex, marital status, and work setting. This may explained by the fact that, nursing is a progressive field which requires continuing learning for junior and senior nurses and providing teaching chances to nurses at each levels. This inconsistent with Lavoie et al., (2018) found the junior nurses have competence in clinical practice higher than their peers who had previous 5 years' experience. Also, Lin \& Wang, (2016) conducted study to evaluate nurses' competence in different units and found dissimilarities in the frequency of practice of the competence between work units.

Moreover, our study results pointed that there was statistical relation significant between therapeutic interventions, managing patient situation domains and total competence and attainment any certification or sharing in advanced life support program like CPR (table 4). This may be due to that nurses who trained reported themselves as quite prepared for practice. This confirmed by Cui et al., (2013) emphasized that training in Advanced Cardiac Life Support give understanding about signs, symptoms, and interventions that must be conducted in lifethreatening situations. Also, ReBueno et al., (2017) mentioned that achieving specialty certification may influence development of expert practice, stimulates 
superiority nursing care and proves positive patients outcome.

On other hand, our study results revealed that there were positive statistical relations between significant managing patient situation domains and achieve training in different specialty (table 4). In accordance with this finding Benner (2001) cited in Berhanu et al., (2016) indicated that contact to clinical experiences increase understanding and skills and expected competence, and nurses when work in different areas attain practical base from which can act.

In addition to that, our study findings didn't indicated any significant relation between benefit of review session in practice and therapeutic interventions, managing patient situation domains and total competence. This may attribute to, showing the review session is benefit for junior and senior nurses. This finding supports the previous study by Donna, (2013) who concluded that case review session was not correlated with nurses' clinical competence. In contrast, Berhanu et al., (2016) concluded that activities lab attendance, section attendance, and awareness to the clinical education setting were features correlated with clinical competence.

Lastly, the results of Figure 2 showed that there was a positive correlation of statistical significance between therapeutic interventions and managing patient situations domains. This may explained by the fact that managing patient situations based on therapeutic interventions and are integrated with each other. This finding, congruence with Stark, (2019) emphasized that comprehensive patient's management department with a highly skilled team to manage patient situations is essential for improve therapeutic interventions and the success in any health setting.

\section{Conclusion}

1. The study clarified that more than two third of the studied nurses had good level of clinical competence.

2. The highest mean scores of managing patient situations domains were related to; reporting the results to the physician and other healthcare members, understanding reason for actions and orders, preparing resources to help in delivery of patient care and communicate relevant information about patient's health situation while, the lowest means score were related to; updating nursing care plan, replicating on your procedure of managing fluctuating patient situations and conclude knowledge from the experience to use it in managing new patient situations.
3. Education level, years of experience in units, attainment any certification or training or sharing in advanced life support program like CPR and achieve training in different specialty were factors linked to clinical competence and influenced it. While case review session and work setting did not significantly associated with clinical competence.

\section{Recommendations}

1. Nurses Managers must plan educational programs to develop nurses' competence from good level to excellent.

2. Policy maker should introduce developmental enterprises to support in professional growth and link to patients' management and finally, evaluated by patient consequences.

3. Nurses Managers must be developing new strategies to expand nurse's knowledge base regarding their role and foster their competence in managing patient situations and evaluate their roles and functions.

4. Nursing educators must develop courses about competence and the competence theory must be applied in practical training that may assist muses in developing the skills required for effective managing patient situations.

5. Nursing Managers must provide opportunity for nurses to achieve training in different specialties as incentive for professional growth and increase a number of nurses with bachelor's degree graduates in hospital for confronting increasing demands of patient care.

6. Nursing educators should develop strategies to enhance nursing competency and investigate the area of self-perceived competence in nursing education based on their systematic literature review and providing educational programs about case review sessions, and reflection process to maximize benefits.

7. Nursing administrators should organize nurses for success by establishing systems for warranting chances for knowledge and skills acquirement required for safety nursing practice and the high health level services.

8. Furthermore, future studies are required to recognize policies of teaching that will help the improvement of nurses' competence and which links nurses' awareness of competence to specific levels of teaching and training programs and patient consequences to increase the educational abilities and clinical practice. Also to examine proficient nurses' views about aspects which impact their achievement of quality performance and to detect techniques to increase and evaluate 
critical thinking in the cognitive domain of competency.

\section{References}

- Aiken, L., Cimiotti, J., Sloane, D., Smith, H., Flynn, L. \& Neff, D. (2013): Effects of Nurse Staffing and Nurse Education on Patient Deaths in Hospitals with Different Nurse work Environments. Medical Care, 49 (12), Pp.10471053.

- American Nurse Association (ANA): (2012): Nursing Scope and Standards of Practice. $2^{\text {nd }}$ ed., http://www.nursingworld.org/scopean Standards of Practice (Last accessed July 15, 2017).

- Benner, B. (2001): From Novice to Expert. Excellence and Power in Clinical Nursing Practice, Prentice-Hall, Upper Saddle River, NJ, USA, 2001.

- Benner, P. (1984): From Novice to Expert: Excellence and Power in Clinical Nursing Practice. Menlo Park, California: AddisonWesley.

- Beogo, I., Mendez, B., Gagnon, M. \& Liue, Y. (2016): Psychometric Evaluation of the French Version of the Clinical Nursing Competence Questionnaire: A Cross-sectional Study in Nursing Education in Burkina Faso. Nurse Educ. Today 2016, Pp. 45, 173-178.

- Berhanu B., Berihun A., Bewket T. Tiruneh, M., Mekonnen K. \& Netsanet, H. (2016): Perceived Clinical Competence among Undergraduate Nursing Students in the University of Gondar and Bahir Dar University, Northwest Ethiopia: Hindawi Publishing Corporation Advances in Nursing, Volume 2016, Article ID 9294673, 7 Pages http://dx.doi.org/10.1155/2016/9294673.

- Blackburn, J., Ousey, K., \& Stephenson, J. (2019): Nurses' Education, Confidence, and Competence in Appropriate Dressing Choise. Adv. Skin Wound Care 2019, Pp. 32, 470-476.

- Blazun, H., Kokol, P., \& Vosner, J. (2015): Research Literature Production on Nursing Competences from 1981 till 2012: A bibliometric Snapshot. Nurse Education Today, 35 (5), Pp. 673-679.

- Carrington, J. \& Effken, J. (2017): Powers and Restrictions of the Electronic Health Record for Documenting Patient Progress. Computers, Informatics, Nursing, 29 (6), Pp. 360-367.

- Cui J, Zhou L, Zhang L, Li L, \& Zhao J. (2013): Training the trainer: an educational course for training pain nursing specialists supported by the International Association for the Study of Pain (IASP). Pain Manag Nurs
Official J Am Soc Pain Manag Nurses 2013; 14 (4): Pp. 33-94.

- Donna, D. (2013): Nurses Perceptions of their Competence in Managing Patient Situations in Acute Care. A Dissertation Submitted in Partial Fulfillment of the Requirement for the Degree of Doctor of Philosophy in Nursing. https://digitalcommons.uri.edu/oa_diss/13

- European Federation of Nurses Association (EFN) (2013): Guideline for the Implementation of Article 31 of Directive 2005/36/EC on the Mutual Recognition of Professional Qualifications, as Amended by Directive 2013/55/EU, in National Nursing Training Programmes. 2015. Available online: http://www.efnweb.be/wpcontent /uploads/EFNCompetences-Framework-ES.compressed.pdf (accessed on 8 April 2019).

- Fuentes, C., Ballester, D., Gelabert, S, Bosch, C. \& Bonmatí, A. (2017): Nursing student and professor perceptions and assessments of the achievement of practicum competencies: A mixed method approach. Nurse Educ. Today, Pp. 45, 199-205.

- Foronda, C., MacWilliams, B., \& McArthur, E. (2017): Interprofessional Communication in Healthcare: And Integrative Review. Nurse Educ. Pract. 2016, Pp.19, 36-40.

- International Council of Nurses (2016): Continuing Competence as a Professional Responsibility and Public Right, International Council of Nurses 2016.

- Iolya, B. (2014): Northern Rural Nurses' SelfPerceived Competence in Addressing the Spiritual Needs of Patients With Life-Limiting Conditions by Using A Palliative Approach. A Capstone Project Submitted in Partial Fulfillment of the Requirement for the Degree of Master TER of Science in Nursing in the School of Graduate Studies. Trinity Western University September 2014 () Ibolya Agoston, 2014. P. 21.

- Kajander, U. (2014): Nurse Competence of Graduating Nursing Students, Department of Nursing Science, Faculty of Medicine, University of Turku, Finland Annales Universitatis Turkuensis, Painosalama Oy, Turku, Finland, 2015 P.78.

- Kielo, E., Salminen, L., \& Stolt, M. (2016): Graduating Student nurses' and Student Podiatrists' Wound care competence: An integrative Literature Review. Nurse Educ. Pract. 2018, Pp.29, 1-7.

- Lane, D. \& Ross, V. (2016): Defining Competencies and Performance Indicators for Physicians in Medical Management," American 
Journal of Preventive Medicine, vol. 14, no. 3, Pp. 229- 236.

- Lavoie, P., Michaud, C., Belisle, M., Boyer, L., Gosselin, É., Grondin, M., Larue, C., Lavoie, S. \& Pepin, J. (2018): Learning Theories and Tools for the Assessment of Core Nursing Competencies in Simulation: A theoretical Review. J. Adv. Nurs. 2018, Pp. 74, 239-250.

- Levy-Malmberg, R. (2014): The Enhancement of Clinical Competence through Caring Science. Scandinavian Journal of Caring Sciences, 28 (4), Pp.861-866.

- Lima, S. Newall, F. Jordan, H.L. \&.Hamilton, B. (2014): How Competent is they? Graduate Nurses' Self-assessment of Competence at the Start of their Careers. Collegian 2014, 21, Pp. 353-358.

- Lin, L. \& Wang, R. (2016): Patient Education Competence Scale for Registered Nurses in Taiwan: Scale Development and Psychometric Validation. Jpn J Nurs Sci 2016: Pp. 1-9.

- Lisa, T. (2019): "Improving Nurse-to-Nurse Handoff Communication at the Bedside through Simulation-Based" (2019). Doctor of Nursing Practice Capstone Projects. 39. https://encompass.eku.edu/dnpcapstones/39

- Meretoja, R, Isoaho, H, \& Leino-Kilpi, H. (2004): Nurse Competence Scale: Advance and Psychometric Analysis. J Adv Nurs. [Cited 2016 Nov 03];47(2):124-33. Available from: https://www.ncbi.nlm.nih.gov/pubmed/15196186

- Meretoja, R. \& Koponen, L. (2012): A systematic Model to Compare Nurses' Optimal and Actual Competencies in the Clinical Setting. Journal of Advanced Nursing, 68(2), Pp.414422.

- Nandi-Ndeitwa, N. (2008): Gender Strategy for Local Government in Namibia. Ministry of Gender Equality and Child Welfare. Windhoek: Nam print. cited in Sabra, H. Abo-Elmagd., N. \& Gawad, S. (2018): Organizational Variables Influencing Nurses' Performance at Quena General Hospital, IOSR Journal of Nursing and Health Sciencee- ISSN: 2320-1959.p- ISSN: 2320-1940 Volume 7, Issue 3 Ver. X (May-June .2018).

- Notarnicola, I., Petrucci, C., De Jesus Brabosa, M.R., Giorgio, F., Stievano, A., \& Lancia, L. (2016): Clinical competence in nursing: A concept analysis. Professional

- Numminen, O., Leino, H., Isoaho, H., \& Meretoja, R. (2017): Development of Nurses' Professional Competence Early in Their Career:
A Longitudinal Study. The Journal of Continuing Education in Nursing, 48 (1), Pp.29-39.

- O'Connell, J., \& Gardener, G. (2014): Beyond Competencies: Using a Capability Framework in Developing Practice Standards for Advanced Practice Nursing. Journal of Advanced Nursing, 70 (12), Pp.2728-2735.

- Pijl-Zeiber, E.M., Barton, S., Konkin, J., Awosoga, O., \& Caine, V. (2014): Competence and competency-based nursing education: Finding our way through the issues. Nurse Education Today, 34 (5), Pp. 676-678.

- ReBueno, M., Tiongco, \& Macindo, J. (2017): A Structural Rquation Model on the Attributes of a skills enhancement Program Acting Clinical Competence of Pre-graduate Nursing Students. Nurse Educ.Today 2017, 49, 180-186.

- Sharp, S., McAllister, M., \& Broadbent, M. (2016): The vital blend of clinical competence and compassion: How patients experience person centered care. Journal of Contemporary Nurse, 52 (2-3), P. 300-

- Stark, P. (2019):"Adopting Complex Case Management Competencies". Doctor of Nursing Practice (DNP) Projects. 194. https://repository.usfca.edu/dnp/194

- Wangensteen, S., Johansson, I. and Nordstrom, G. (2010): Nurse Competence Scale -Psychometric Testing in a Norwegian context. Nurse Education in Practice.

- Zhang, J. Ye., W. \& Fan, F. (2015): Development of a self-assessment tool for measuring competences of obstetric nurses in rooming-in wards in China. Available from: https://www.ncbi.nlm.nih.gov/ pmc/articles/PMC4694368/pdf/ijcem000818548.pdf 